\title{
DEVELOPMENT AND VALIDATION OF RP-HPLC METHOD FOR THE SIMULTANEOUS ESTIMATION OF DARUNAVIR AND COBICISTAT IN COMBINED TABLET DOSAGE FORMS
}

\author{
P. Nagaraju*, S. Ravi Chandra, B. Pavithra, SK. Akhil and SK. Altaf \\ Department of Pharmaceutical Analysis, Hindu College of Pharmacy, \\ Amaravathi Road, Guntur - 522 002, Andhra Pradesh, India.
}

\begin{abstract}
The study describes method development and subsequent validation of RP-HPLC method for simultaneous estimation of darunavir and cobicistat in combined tablet dosage forms. Chromatographic separation was achieved Inertsil ODS C18 column (150 mm x $4.6 \mathrm{~mm}, 5 \mu \mathrm{m})$ using a mobile phase consisting of $(30: 70 \mathrm{v} / \mathrm{v}) 0.1 \%$ TEA: methanol at a flow rate of $1.2 \mathrm{~mL} / \mathrm{min}$. The detection wavelength is $242 \mathrm{~nm}$. The retention times of darunavir and cobicistatwere found to be $3.237 \mathrm{~min}$ and $4.805 \mathrm{~min}$ respectively. The developed method was validated as per ICH guidelines. The developed and validated method was successfully used for the quantitative analysis of darunavir and cobicistat in tablet dosage forms.
\end{abstract}

Keywords: RP-HPLC, Darunavir, Cobicistat and validation.

\section{INTRODUCTION}

Darunavir chemically,[(3aS,4R,6aR)2,3,3a,4,5,6a-hexahydrofuro[2,3 b]furan-4yl]N-[(2S,3R)-4-[(4-aminophenyl)sulfonyl- (2methylpropyl)amino]-3-hydroxy-1-phenylbutan2- yl] carbamate and its molecular formula is $\mathrm{C}_{17} \mathrm{H}_{19} \mathrm{~N}_{3} \mathrm{O}_{3} \mathrm{~S}$. It is a protease inhibitor used to treat HIV. It acts on the HIV aspartyl protease which the virus needs to cleave the HIV polyprotein into its functional fragments (Figure-1). Cobicistat chemically, (1,3-thiazol5-yl)methylN-[(2R,5R)-5-[(2S)-2-\{[methyl(\{[2(propan-2-yl)-1,3-thiazol-4-yl]methyl\}) carbamoyl] amino\}-4-(morpholin-4yl)butanamido]-1,6-diphenylhexan-2-yl] carbamate (Figure-2) and its molecular formula is $\mathrm{C}_{40} \mathrm{H}_{53} \mathrm{~N}_{7} \mathrm{O}_{5} \mathrm{~S}_{2}$. It is indicated for treating infection with human immunodeficiency virus (HIV). Although it does not have any anti-HIV activity, cobicistat acts as a pharmacokinetic enhancer by inhibiting cytochrome P450 3A isoforms (CYP3A) and therefore increases the systemic exposure of coadministered agents that are metabolized by CYP3A enzymes. More specifically, cobicistat is indicated to increase systemic exposure of atazanavir or darunavir (once daily dosing regimen) in combination with other antiretroviral agents in the treatment of HIV-1 infection. Increasing systemic exposure of antiretrovirals (ARVs) without increasing dosage allows for better treatment outcomes and a decreased side effect profile.A few chromatographic $^{1-7}$ methods have been reported for the simultaneous determination of darunavir and cobicistat in combined dosage forms. The present work is aimed to develop and validate simple, sensitive and more precise RP- HPLC method for simultaneous estimation of darunavir and cobicistat in bulk and pharmaceutical tablet dosage form.

\section{MATERIALS AND METHODS Equipment}

Separation was carried out by using Shimadzu LC20A system equipped with LC20AT pump. SPD 20A Prominence UV-Visible detector and the peak areas were integrated by using spinchrome software CFR. Analysis was carried out on Inertsil C18 $(150 \mathrm{~mm} \times 4.6 \mathrm{~mm}$, $5 \mu \mathrm{m}$ ) column. 


\section{CHEMICALS AND REAGENTS}

HPLC grade methanol, acetonitrile and analytical grade dipotassium hydrogen phosphate, triethylamine and o-phosphoric acid were obtained from $\mathrm{M} / \mathrm{s}$. Rankem Chemicals Ltd, Mumbai, India. Milli-Q water dispensed through a $0.22 \mu$ filter of the Milli-Q water purification system (Millipore, Merck $\mathrm{KGaA}$, Darmstadt, Germany) was used throughout the study.

\section{Preparation of solutions \\ Preparation of $0.1 \%$ triethylamine}

Pipette out $1 \mathrm{ml}$ of TEA into a $1000 \mathrm{~mL}$ beaker, dissolved and diluted to $1000 \mathrm{~mL}$ with HPLC water.

\section{Preparation of Mobile phase}

A mixture of $300 \mathrm{~mL}$ of $0.1 \%$ of TEA and 700 $\mathrm{mL}$ of methanol in the ratio of $30: 70 \mathrm{v} / \mathrm{v} / \mathrm{v}$ was prepared and used as the mobile phase.

\section{Preparation of mixed standard solution of darunavir and cobicistat}

About $80 \mathrm{mg}$ of darunavir and $15 \mathrm{mg}$ of cobicistat were accurately weighed and transferred into a $100 \mathrm{~mL}$ clean dry volumetric flask containing $25 \mathrm{~mL}$ of the mobile phase.The solution was sonicated for $5 \mathrm{~min}$ and then volume was made up to the mark with a further quantity of the diluent to get a concentration of $8000 \mu \mathrm{g} / \mathrm{mL}$ of darunavirand $1500 \mu \mathrm{g} / \mathrm{mL}$ of cobicistat (Stock solution). A mixed working standard solution was further prepared by diluting the above stock solution to obtain a concentration of $800 \mu \mathrm{g} / \mathrm{mL}$ of darunavir and $150 \mu \mathrm{g} / \mathrm{mL}$ of cobicistat.

\section{Preparation of the tablet solution}

Twenty tablets of the commercial sample of 'PREZCOBIX' were weighed and finely powdered. An accurately weighed portion of powdered sample equivalent to $80 \mathrm{mg}$ of darunavir and $15 \mathrm{mg}$ of cobicistat was transferred into a $100 \mathrm{~mL}$ volumetric flask containing $25 \mathrm{~mL}$ of the methanol. The contents of the flask were sonicated for about $10 \mathrm{~min}$ for complete solubility of the drugs and the volume made up with a further quantity of the diluent. Then, this mixture was filtered through a $0.45 \mu$ membrane filter. This filtrate was used for further analysis.

\section{Chromatographic conditions}

A reverse phase column Inertsil C18 column (150 mm x $4.6 \mathrm{~mm}, 5 \mu \mathrm{m}$ particle size), equilibrated with mobile phase $(0.1 \%$ TEA and methanolin the ratio of $30: 70 \mathrm{v} / \mathrm{v}$ ) was used. Mobile phase flow rate was maintained at 1 $\mathrm{mL} / \mathrm{min}$ and effluents were monitored at 242 $\mathrm{nm}$. The sample was injected using 20 micro litre manual sample injector and run time was 9min (Figure 3and 4).

\section{METHOD VALIDATION \\ System suitability}

The system suitability studies were done for parameters like theoretical plates, tailing factor, retention time, resolution by injecting the standard solution in to the optimized chromatographic system for six times and the results are given in the Table 1.

\section{Accuracy}

The standard addition method was used to demonstrate the accuracy of the proposed method. For this purpose, known quantities of darunavir and cobicistat were supplemented to the previously analysed sample solution and then experimental and true values compared. Three levels of solutions were made corresponding to 50, 100 and $150 \%$ of nominal analytical concentration. Standard preparation \& sample preparation was injected into the HPLC and \% RSD fordarunavir and cobicistat peaks in standard preparation was calculated and tabulated in Table 2 and figure 5-7. The mean recovery values of darunavir and cobicistatwere found to be 99.47-100.16 $\%, 99-99.6 \%$ respectively.

\section{Linearity}

Linear calibrations plots of the proposed method were obtained over concentration ranges of $40-200 \mu \mathrm{g} / \mathrm{mL}$ for darunavir, $(40,80$, $120,160,200 \mu \mathrm{g} / \mathrm{mL}$ ) and $7.5-45 \mu \mathrm{g} / \mathrm{mL}$ for cobicistat $(7.5,15,22.5,30,37.5 \mu \mathrm{g} / \mathrm{mL})$. Each solution was prepared in triplicate. Regression coefficient was found to be 0.999 and 0.999 for both the drugs (Figure 8 - 14). Standard curve had a reliable reproducible over the standard concentrations across the calibration range. All back calculated concentrations did not differ from the theoretical value as no single calibration standard point was dropped during the validation.

\section{Precision}

For precision same concentration solution was injected 5 times and observed for any peculiar change in the areas and \% RSD was calculated for each drug.

\section{Method precision}

Five replicate injections of the same dilution were analysed on two different days by different analyst for verifying the variation in the precision. The \% RSD of the results for darunavir and cobicistat were found to be 0.97 and 0.52 respectively, which are within acceptable limit of $\leq 2$. Hence, the method is 
reproducible on different days with different analyst. This indicates that the method is precise. The results are shown in the Table 3 and figure 15-20.

\section{Intermediate Precision}

For system precision study the standard solution replicates was injected repeatedly for six times and was observed. The standard deviation values were found to be 338473 and 110173 for darunavir and cobicistat and the \% RSD values were 1.21 and 0.84 for darunavir and cobicistat and the results are tabulated in the Table 4 and figure 21-26.

\section{Limit of detection (LOD)}

The LOD for this method was found to be 0.78 $\mu \mathrm{g} / \mathrm{mL}$ and $0.09 \mu \mathrm{g} / \mathrm{mL}$ for darunavir and cobicistat respectively.

\section{Limit of quantitation (LOQ)}

The LOQ for this method was found to be 2.37 $\mu \mathrm{g} / \mathrm{mL}$ and $1.16 \mu \mathrm{g} / \mathrm{mL}$ for darunavir and cobicistat respectively.

\section{Robustness}

Robustness is generally done by changing the parameters like flow rate, organic phase of the mobile phase. The results are shown in the following data is given in the Table 5 .

\section{Assay}

Twenty micro liters of standard and sample solutions were injected separately in to the chromatographic system and the peak areas for the analyte peaks were measured. The $\%$ content of each drug was calculated as shown in below table format.

\begin{tabular}{|c|c|c|c|c|}
\hline Brand name & Drug & $\begin{array}{c}\text { Labeled } \\
\text { amount } \\
\text { (mg) }\end{array}$ & $\begin{array}{c}\text { Amount } \\
\text { found } \\
\text { (mg) }\end{array}$ & $\begin{array}{c}\text { \% } \\
\text { assay }\end{array}$ \\
\hline \multirow{2}{*}{ PREZCOBIX } & darunavir & 800 & 798.84 & 99.85 \\
\cline { 2 - 5 } & cobicistat & 150 & 149.16 & 99.44 \\
\hline
\end{tabular}

\section{RESULTS AND DISCUSSION}

To develop a new RP-HPLC method, several mobile phase compositions were tried. A satisfactory separation with good peak symmetry was obtained with zodiac.In the present study, a new simple, precise and accurate HPLC method was developed and validated for the simultaneous estimation of darunavir and cobicistatin tablet dosage forms. In this method, an Inertsil C18 (150 x $4.6 \mathrm{~mm}$; $5 \mu \mathrm{m}$ ) column using mobile phase containing $0.1 \%$ TEA: methanol $(30: 70 \mathrm{v} / \mathrm{v})$ at a flow rate of $1.2 \mathrm{~mL} / \mathrm{min}$. Quantification was achieved with UV detection at $242 \mathrm{~nm}$ based on peak area. The retention time for darunavir and cobicistat were found to be $3.237 \mathrm{~min}$ and 4.805 respectively. The optimized method was validated as per ICH guidelines. The System suitability parameters observed by using this optimized conditions were reported. A linearity range of $40-200 \mu \mathrm{g} / \mathrm{mL}$ with correlation coefficient 0.999 was established for darunavirand $7.5-37.5 \mu \mathrm{g} / \mathrm{mL}$ with correlation coefficient 0.999 was established for cobicistat. The precision of the proposed method was carried in terms of the method precision and intermediate precision of the $\%$ RSD values of darunavir were found to be $0.97 \%, 0.52 \%$ and cobicistat were found to be $1.21 \%, 0.84$ $\%$ and reveal that the proposed method is precise. The LOD and LOQ values for darunavir were $0.78 \mu \mathrm{g} / \mathrm{mL}$ and $2.37 \mu \mathrm{g} / \mathrm{mL}$ and for cobicistat were found to be 0.09 and $1.16 \mu \mathrm{g} / \mathrm{mL}$ receptively. The results of analysis of commercial formulation indicated that there is no interference due to common formulation excipients with the developed method. Therefore, the proposed method can be used for routine analysis of these two drugs in their combined pharmaceutical dosage form.

\section{CONCLUSION}

The proposed method was found to be simple, precise, accurate and rapid for determination of darunavir and cobicistat from pure and its dosage forms. The mobile phase is simple to prepare and economical. The sample recoveries in the formulation were in good agreement with their respective label claims and they suggested non-interference of formulation excipients in the estimation. Hence, this method can be easily and conveniently adopted for routine analysis of darunavir and cobicistat in pure form and its dosage form and also can be used for dissolution or similar studies. 
<smiles>CC(C)CN(C[C@H](O)[C@H](Cc1ccccc1)NC(=O)O[C@H]1CO[C@@H]2OCC[C@@H]21)S(=O)(=O)c1ccc(N)cc1</smiles>

Fig. 1: Chemical structure of Darunavir<smiles>CC(C)c1nc(CN(C)C(=O)N[C@@H](CCN2CCOCC2)C(=O)N[C@H](CC[C@H](Cc2ccccc2)NC(=O)OCc2cncs2)Cc2ccccc2)cs1</smiles>

Fig. 2: Chemical structure of Cobicistat

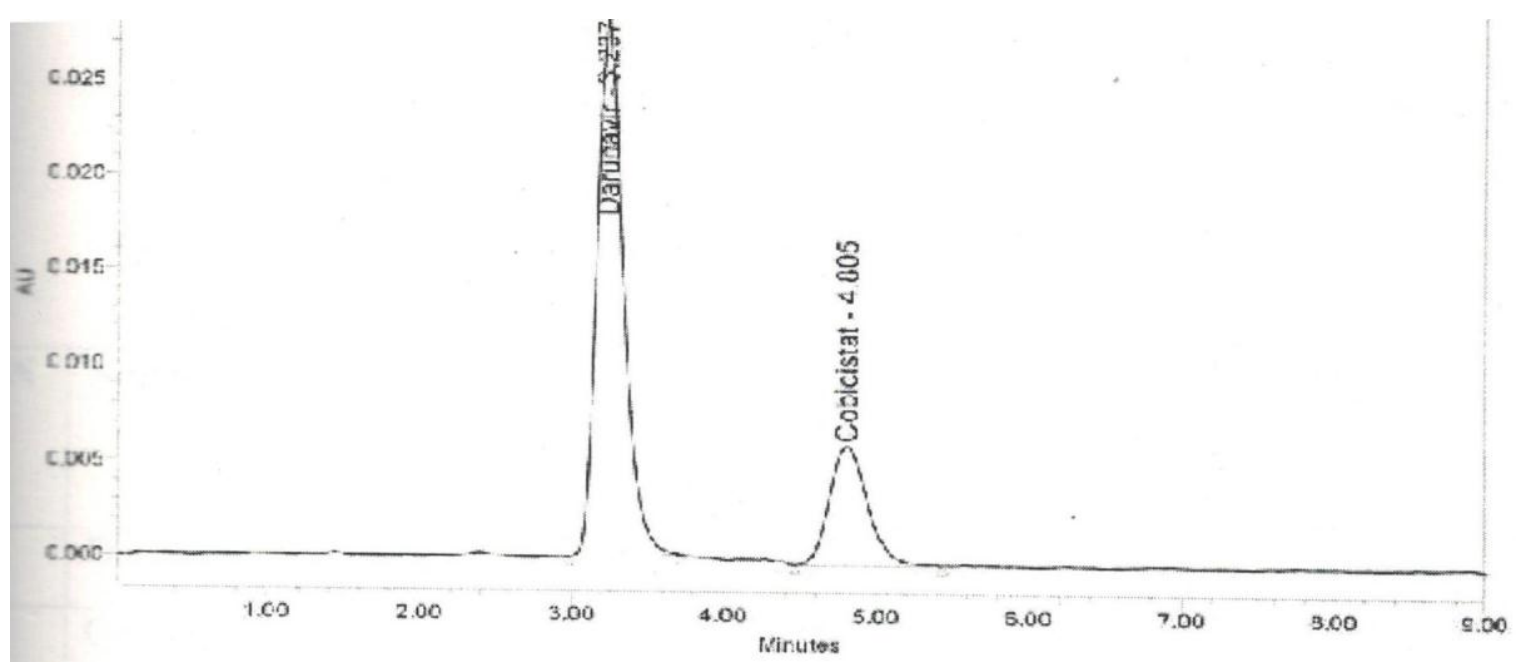

Fig. 3: A typical chromatogram showing the separation of darunavir and cobicistat standard 


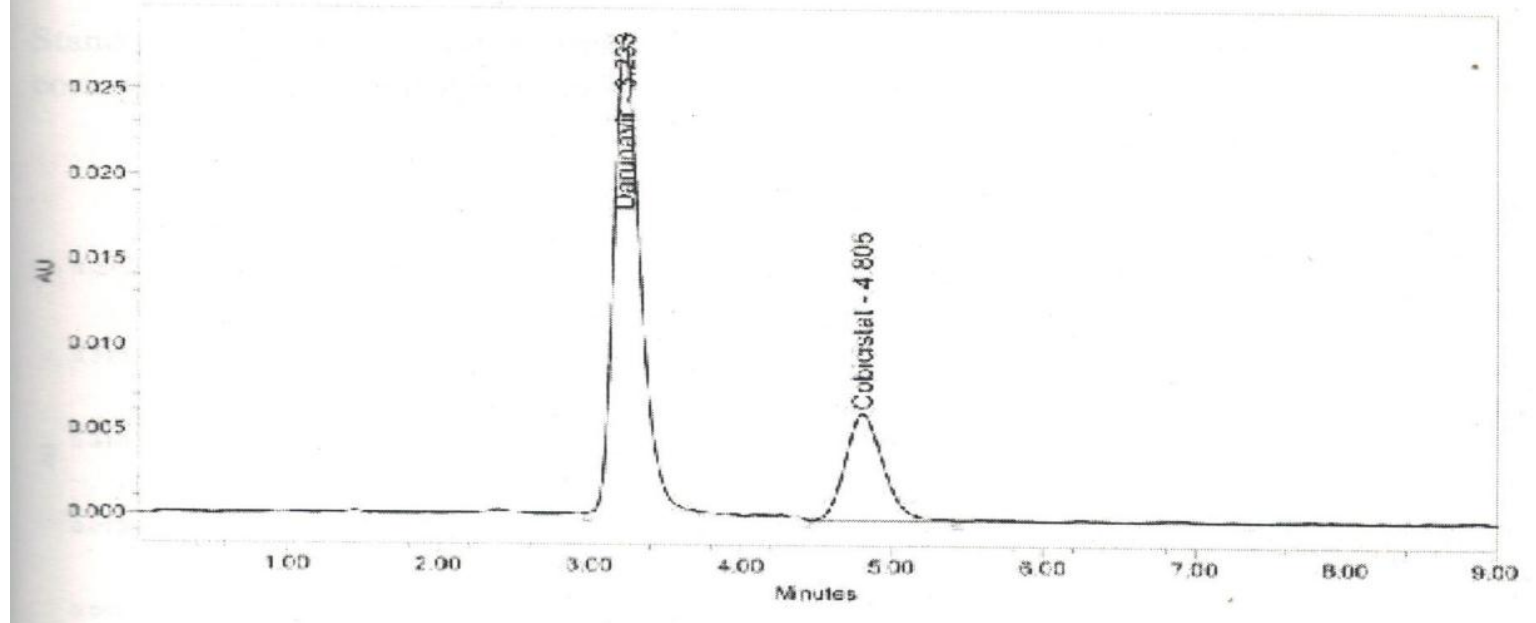

Fig. 4: A typical chromatogram showing the separation of darunavir and cobicistat sample

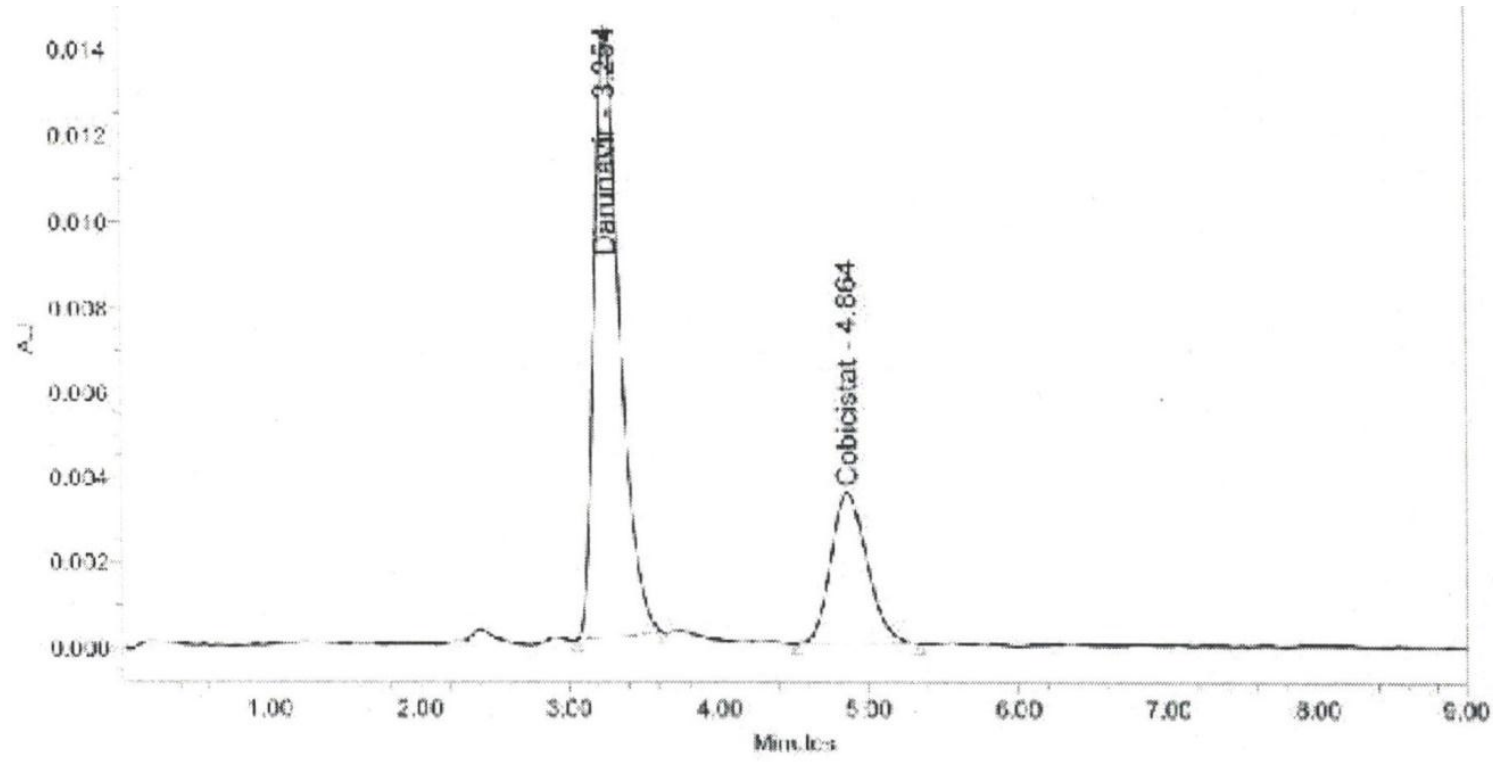

Fig. 5: Chromatogram for accuracy at 50\% level

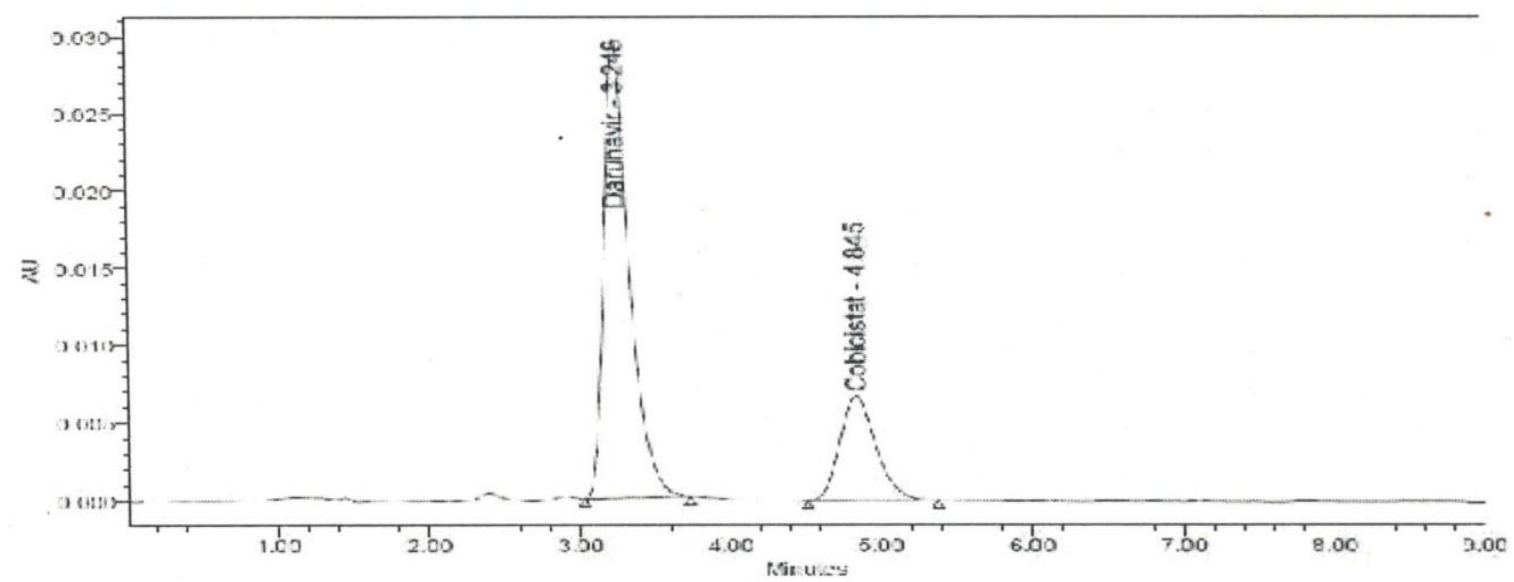

Fig. 6: Chromatogram for accuracy at $100 \%$ level 


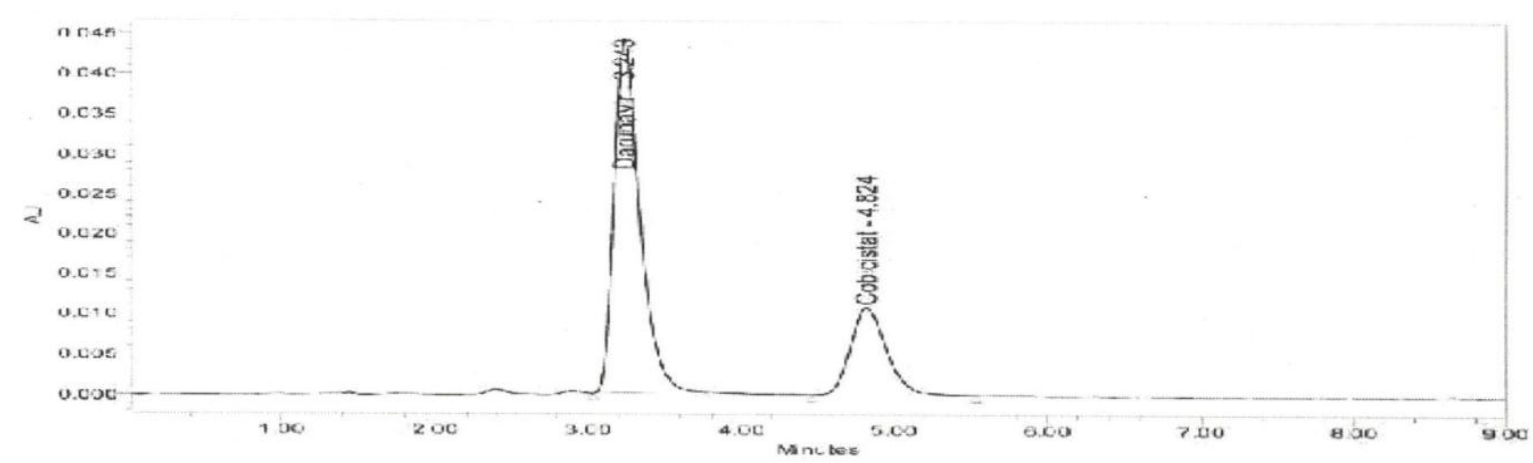

Fig. 7: Chromatogram for accuracy at $150 \%$ level

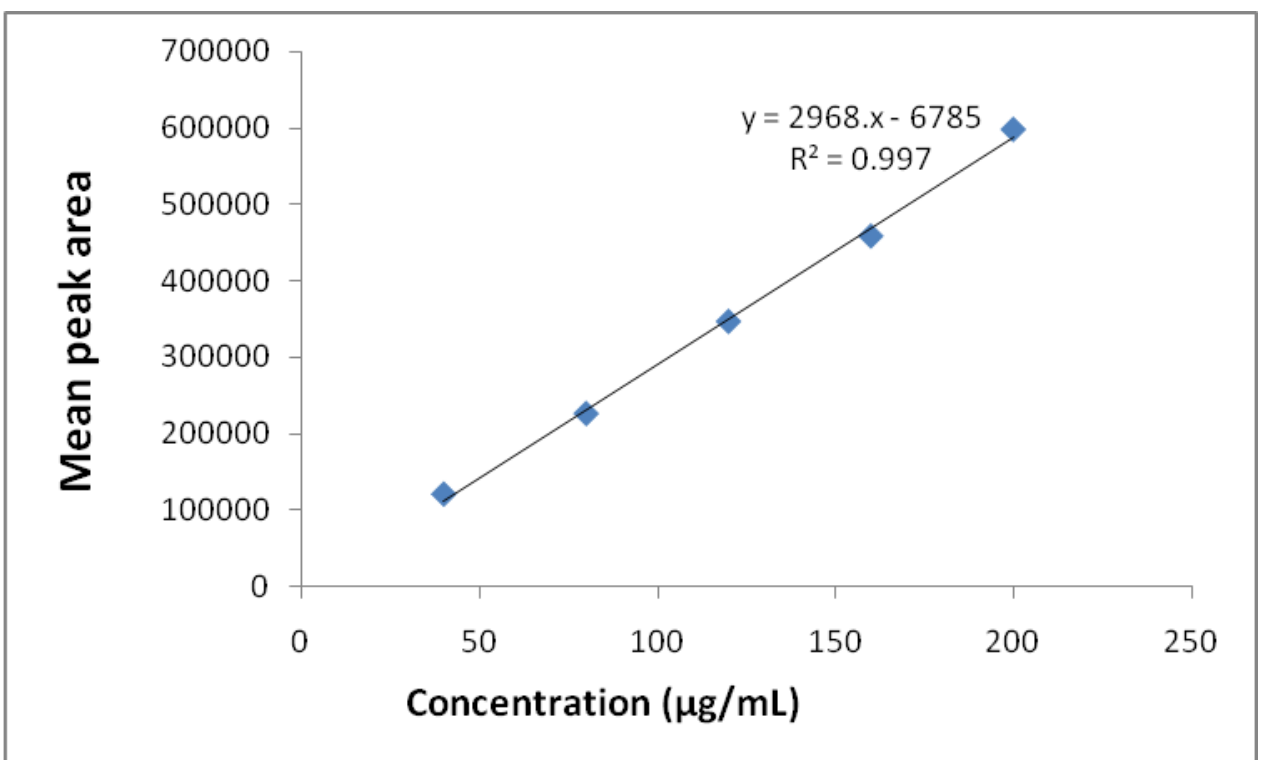

Fig. 8: Calibration curve for darunavir

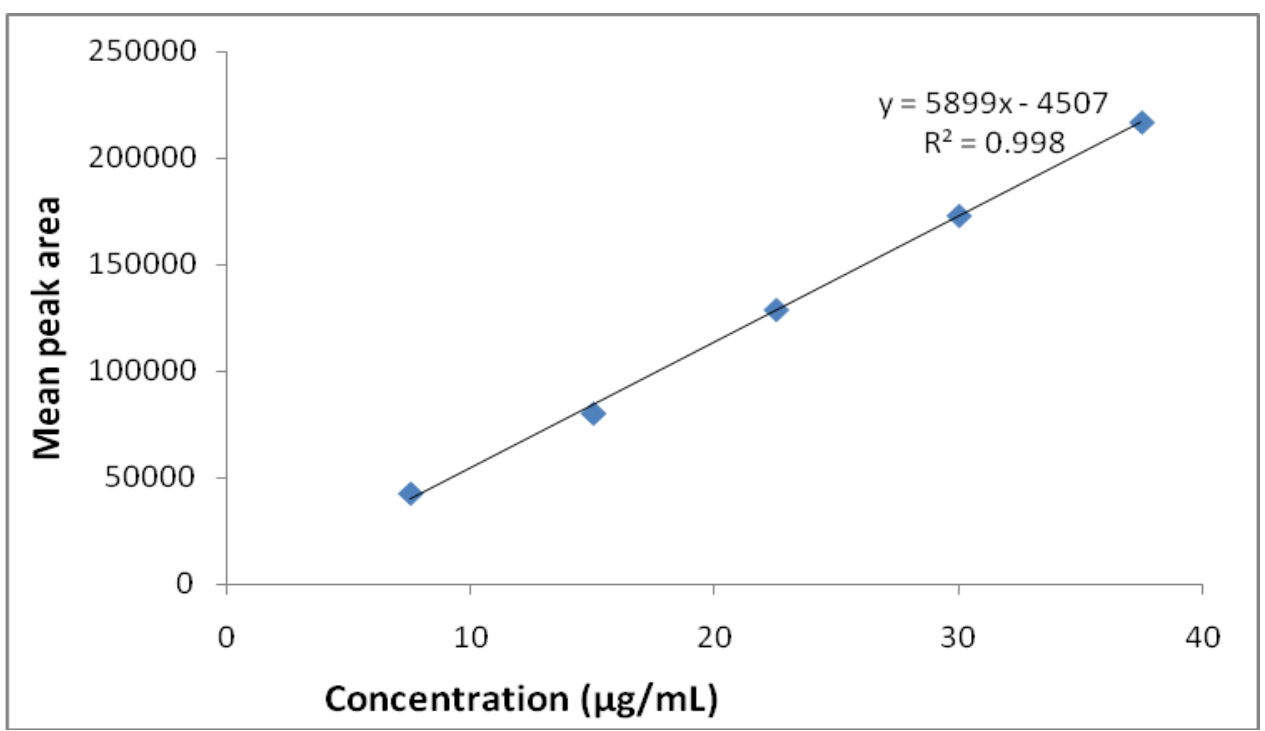

Fig. 9: Calibration curve for cobicistat 


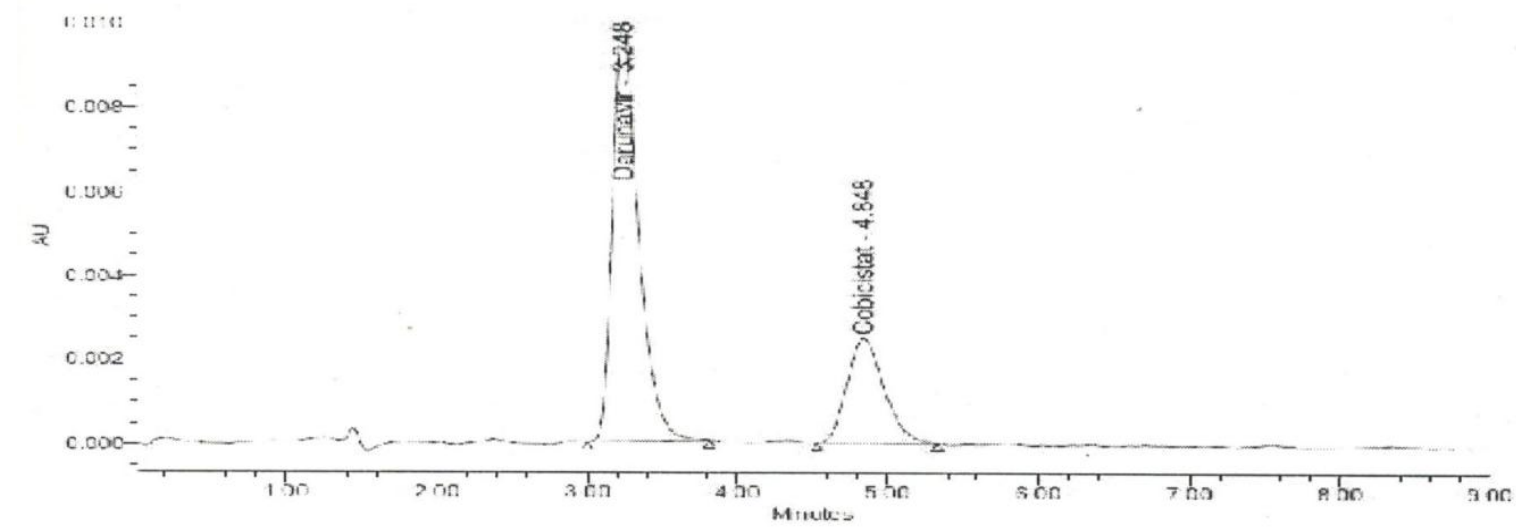

Fig. 10: Chromatogram for linearity at level 1

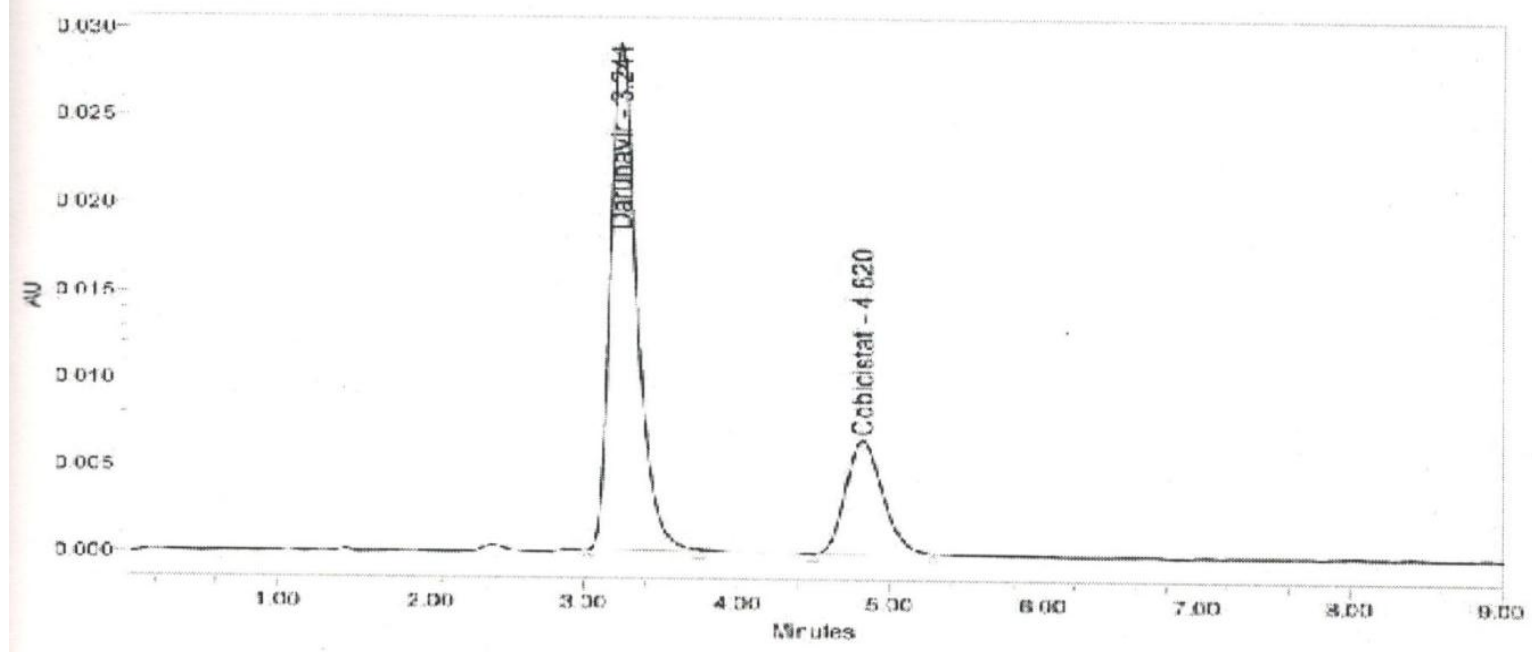

Fig. 11: Chromatogram for linearity at level 2

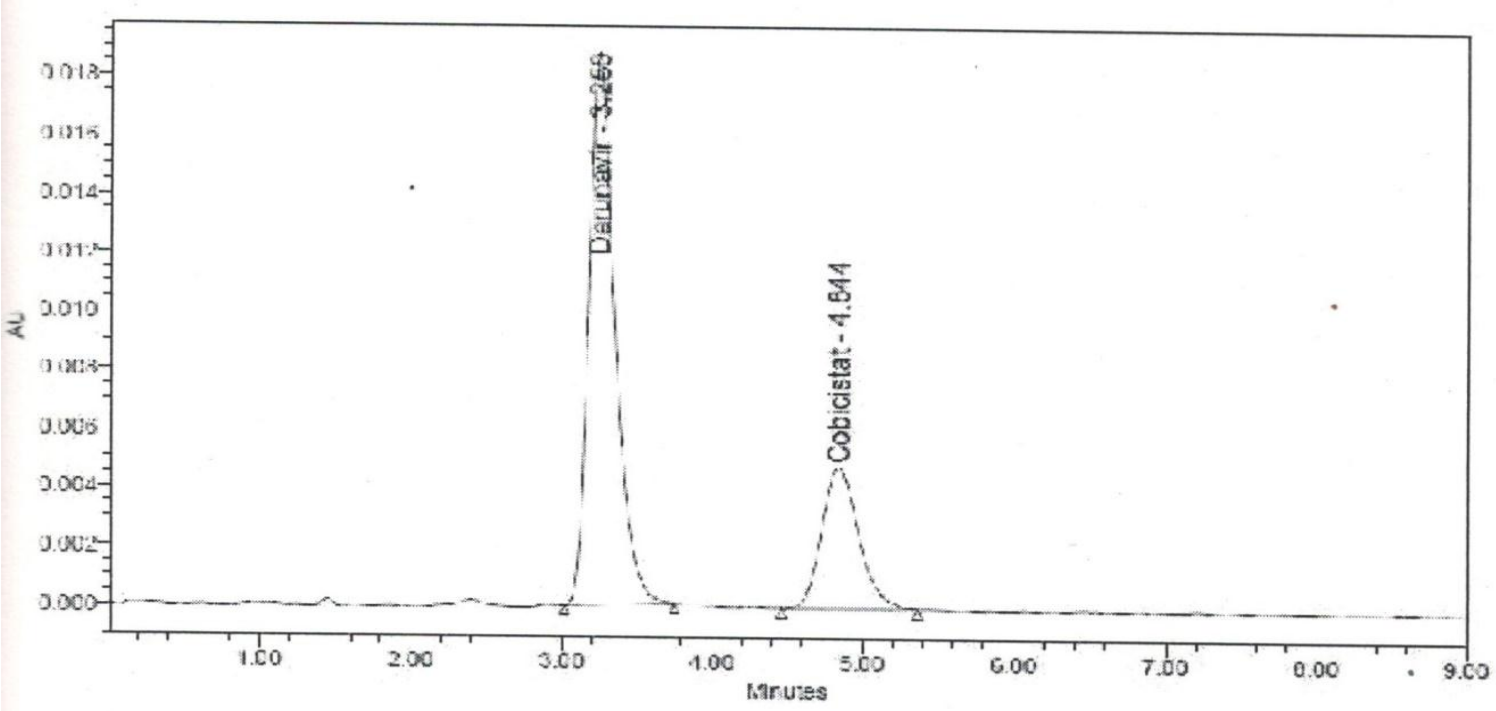

Fig. 12: Chromatogram for linearity at level 3 


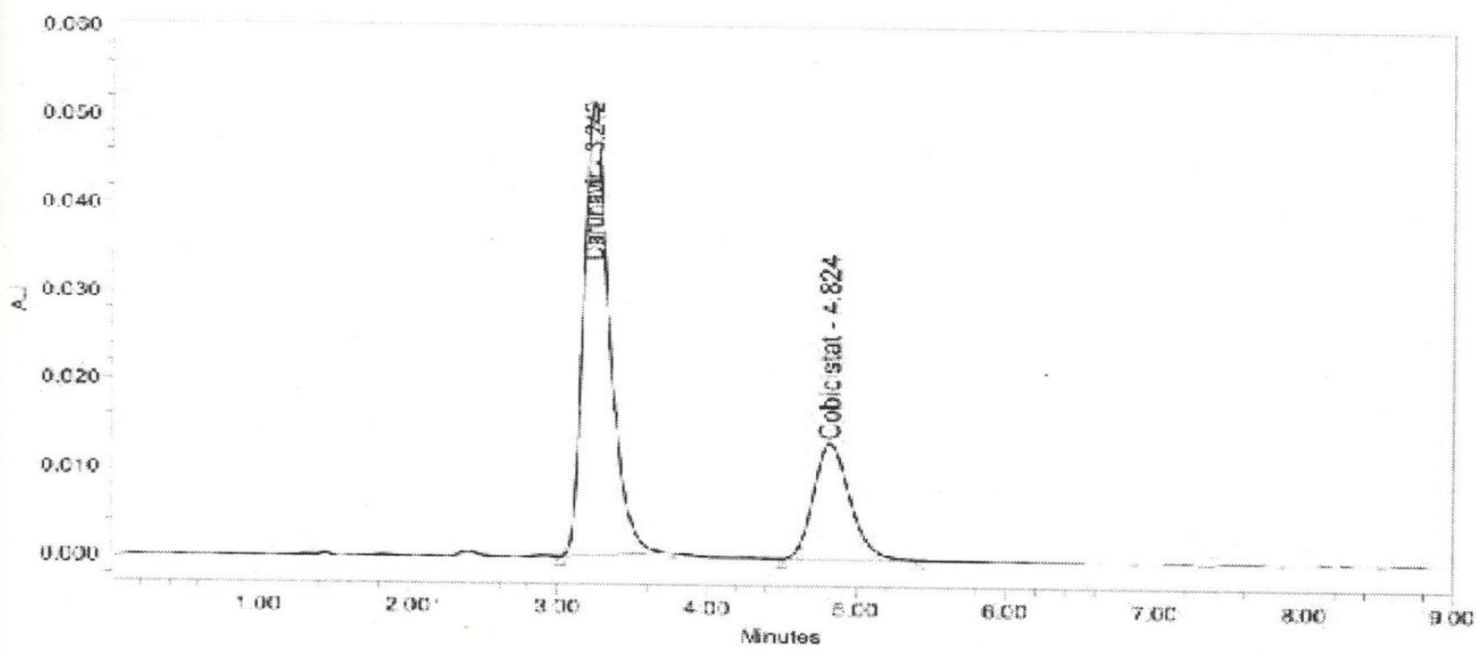

Fig. 13: Chromatogram for linearity at level 4

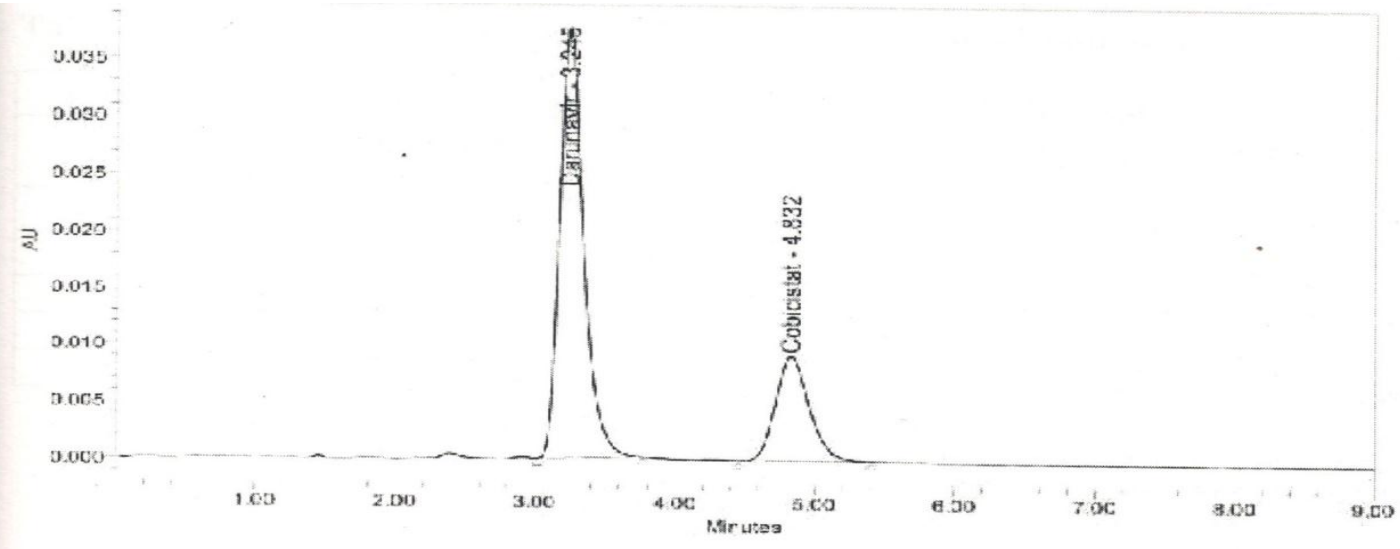

Fig. 14: Chromatogram for linearity at level 5

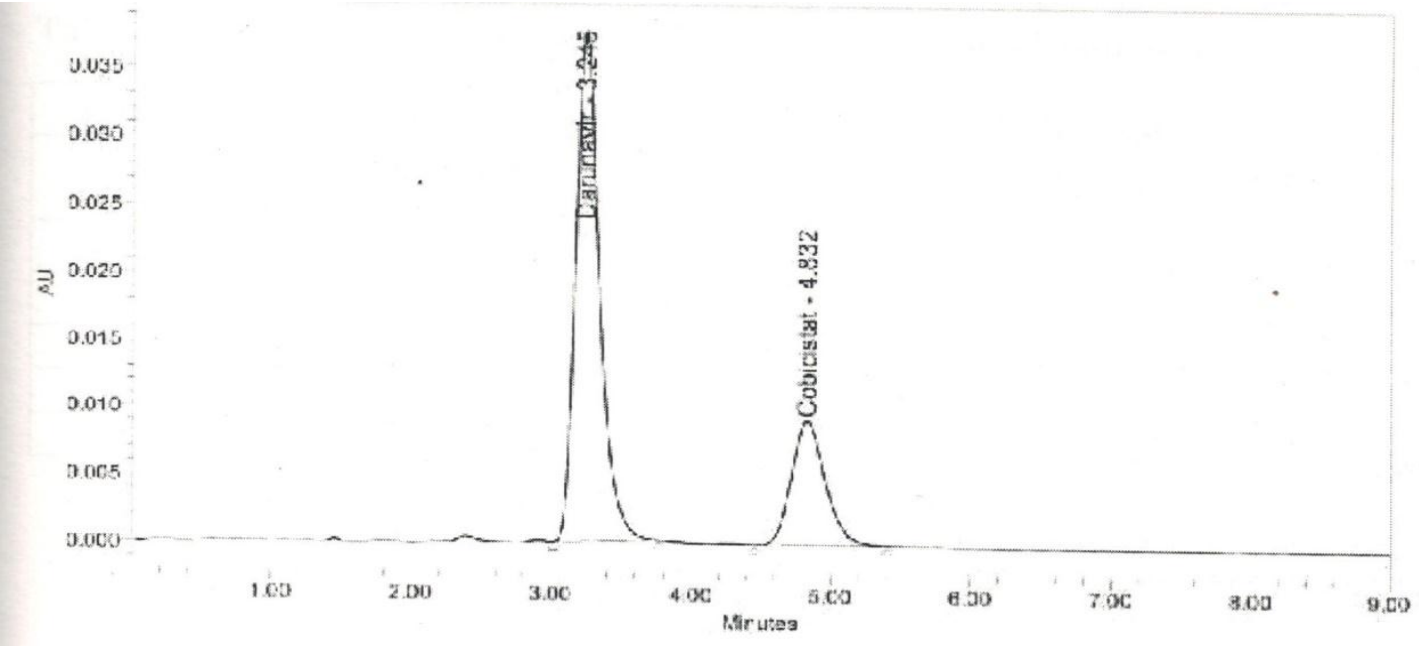

Fig. 15: Chromatogram-1 for method precision of Darunavir and Cobicistat 


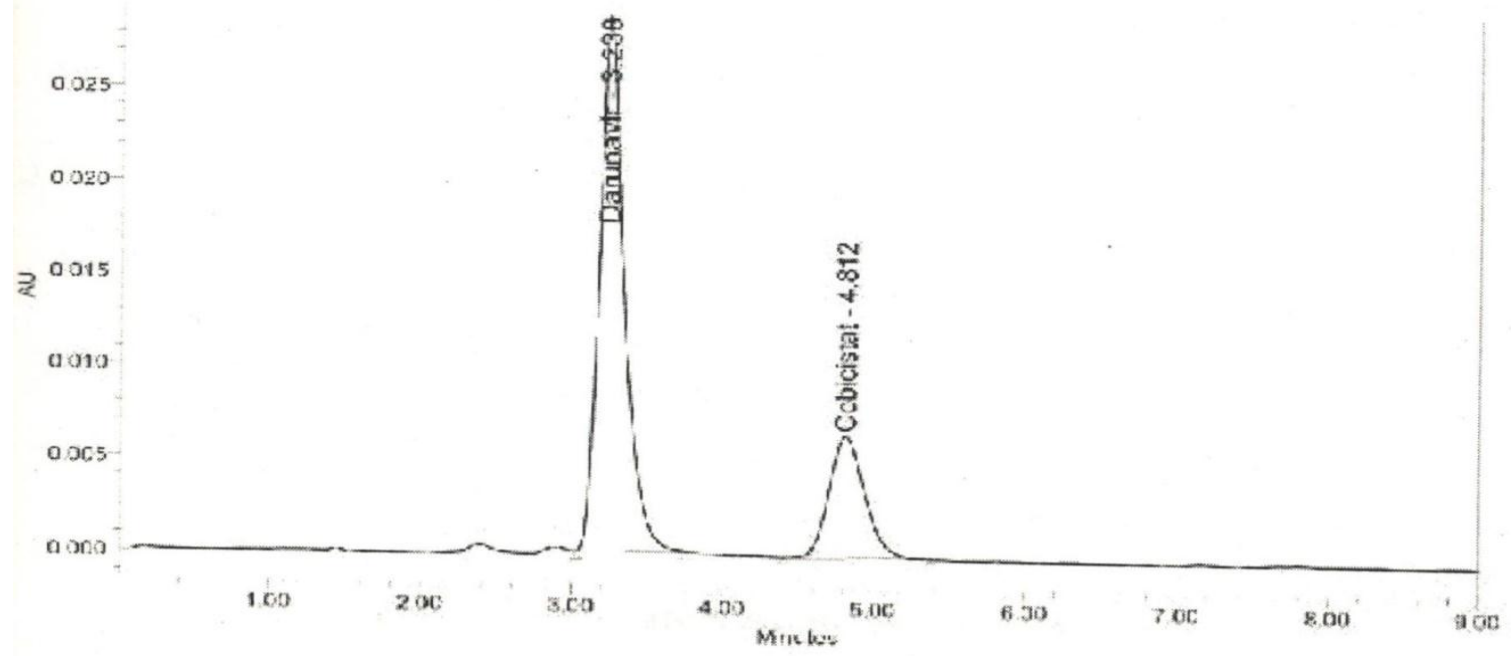

Fig. 16: Chromatogram-2 for method precision of Darunavir and Cobicistat

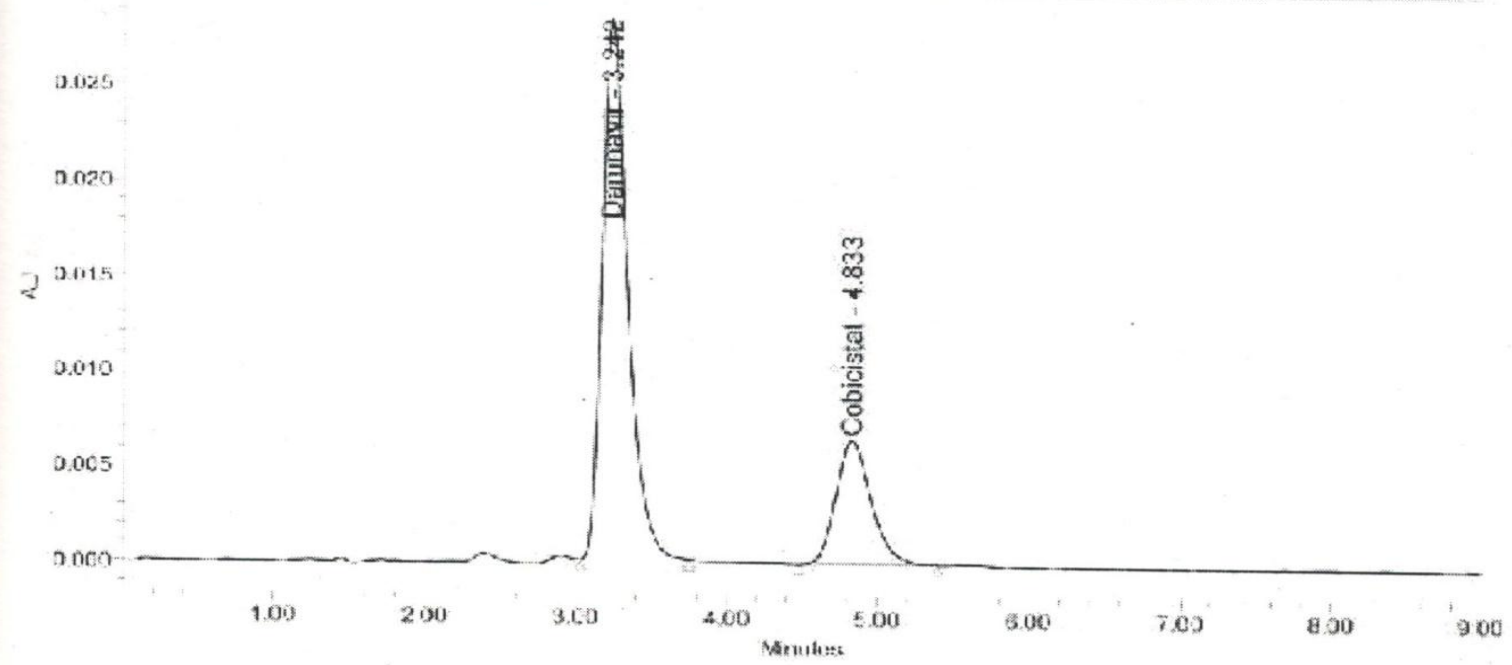

Fig. 17: Chromatogram-3 for method precision of Darunavir and Cobicistat

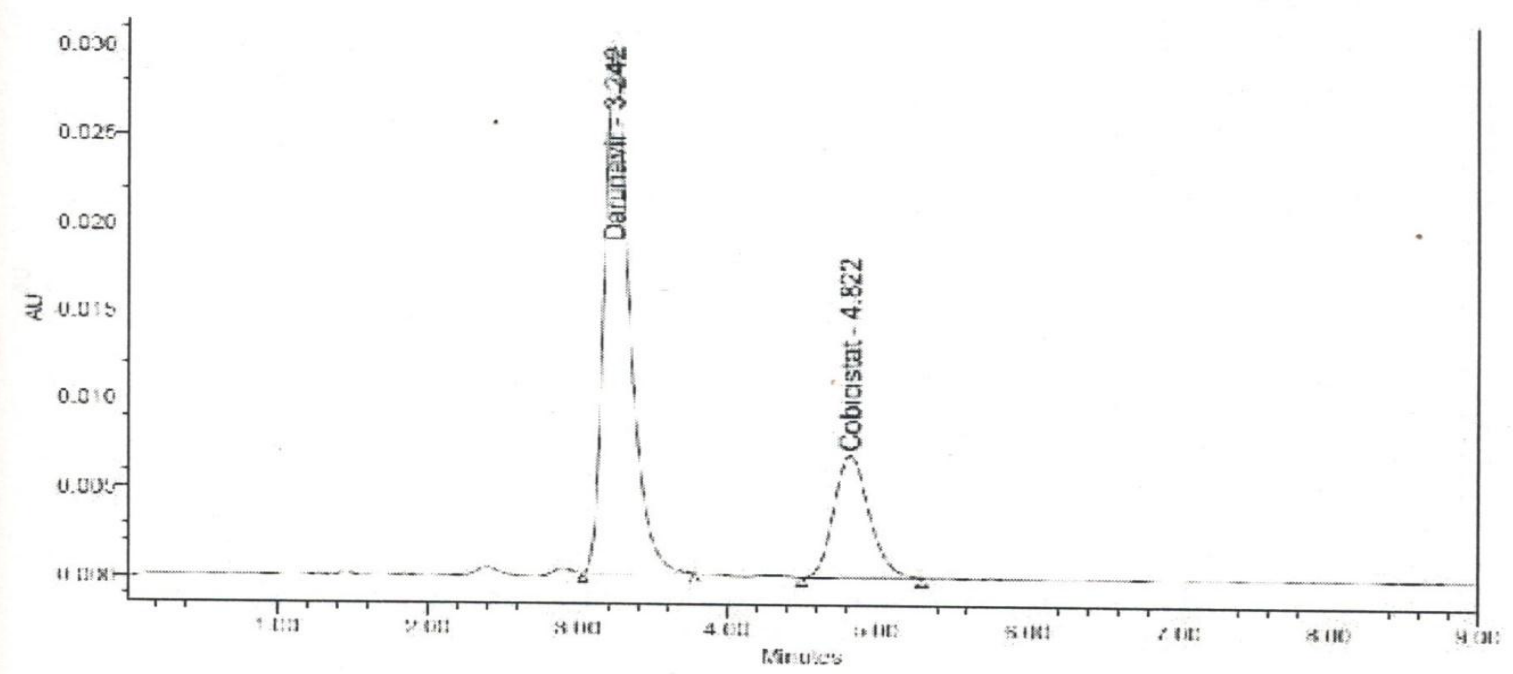

Fig. 18: Chromatogram-4 for method precision of Darunavir and Cobicistat 


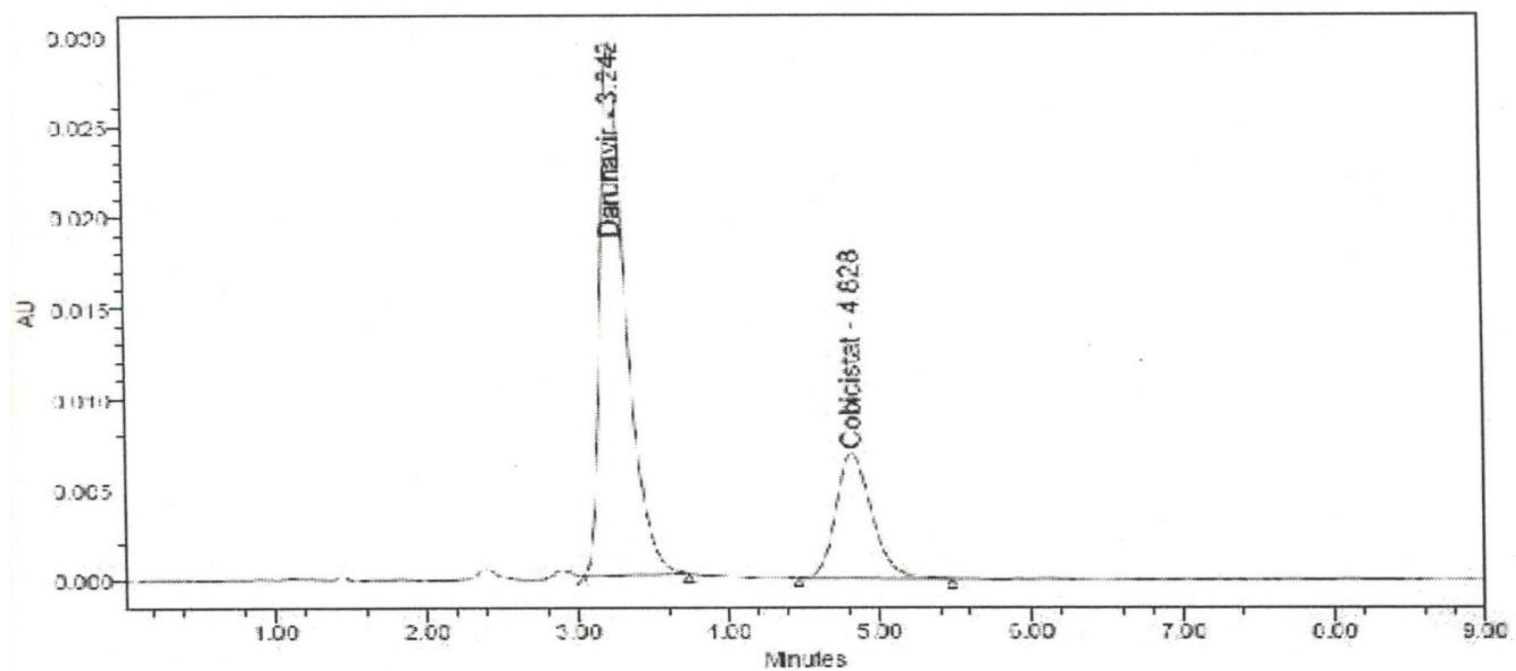

Fig. 19: Chromatogram-5 for method precision of Darunavir and Cobicistat

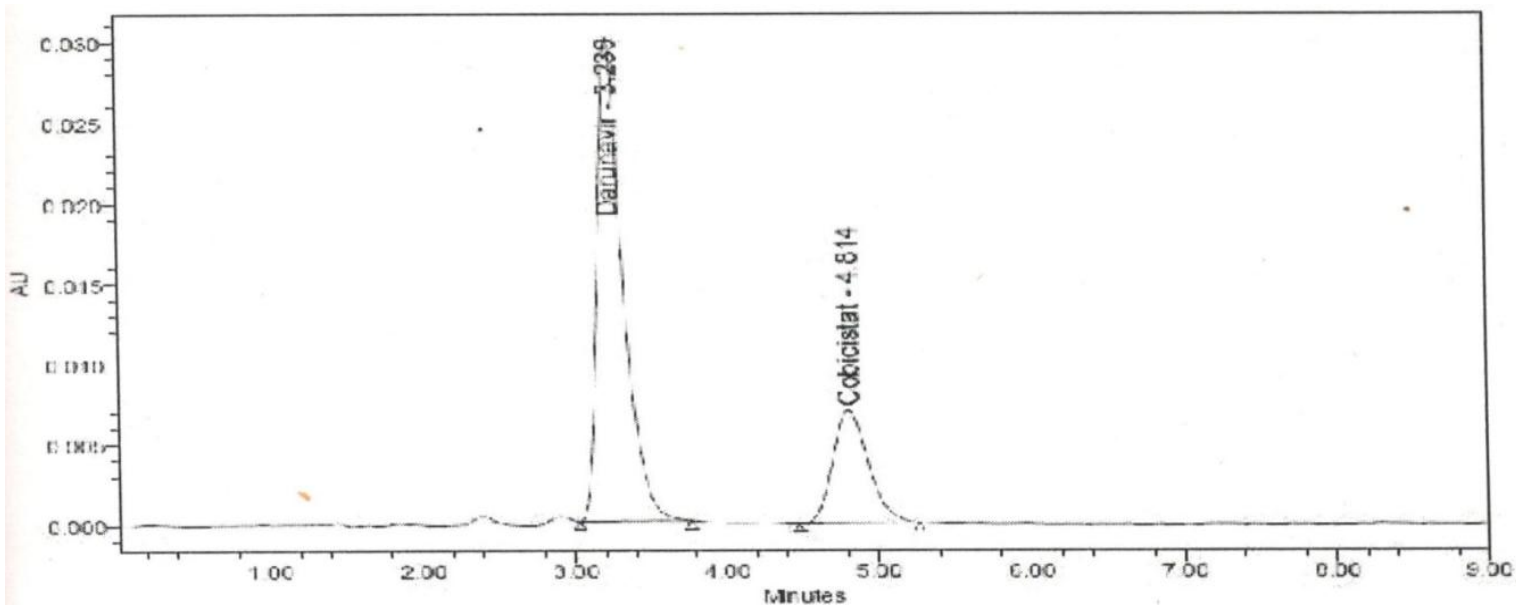

Fig. 20: Chromatogram-6 for method precision of Darunavir and Cobicistat

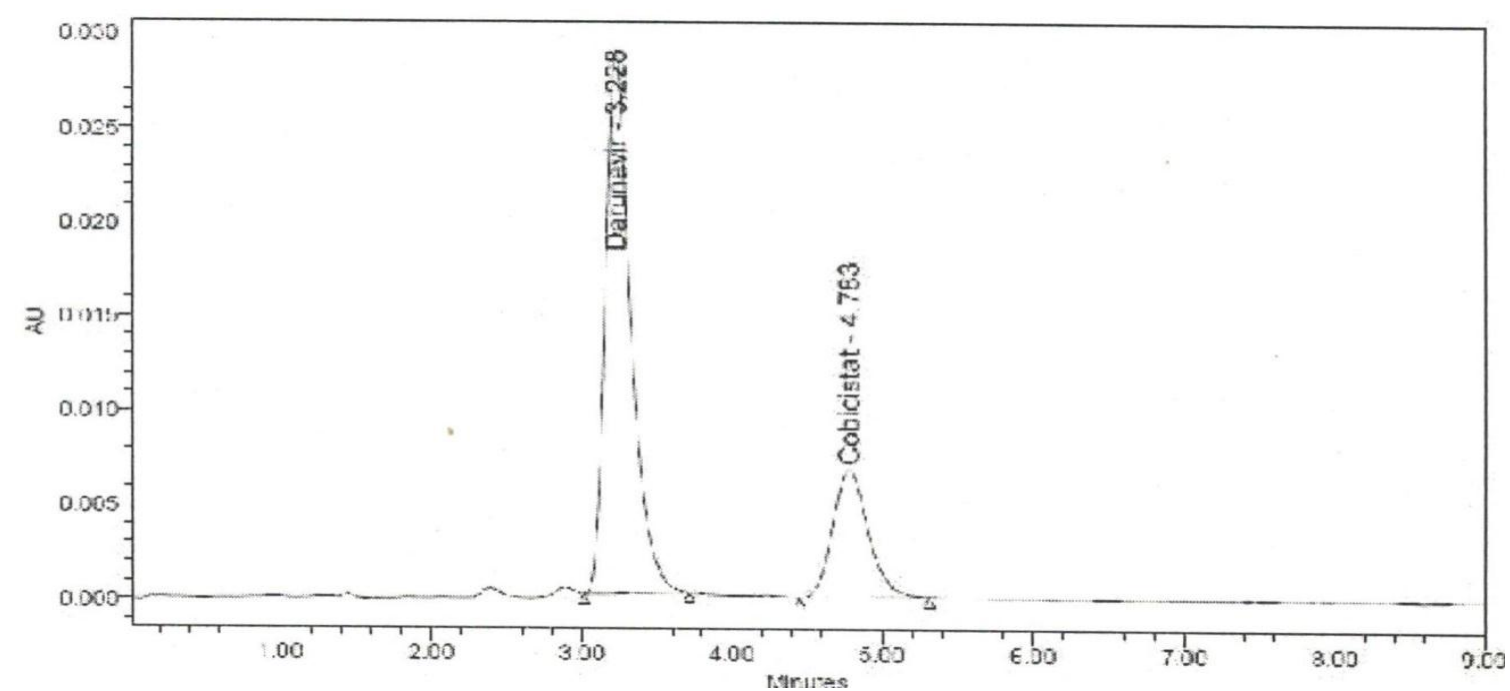

Fig. 21: Chromatogram-1 for intermediate precision of Darunavir and Cobicistat 


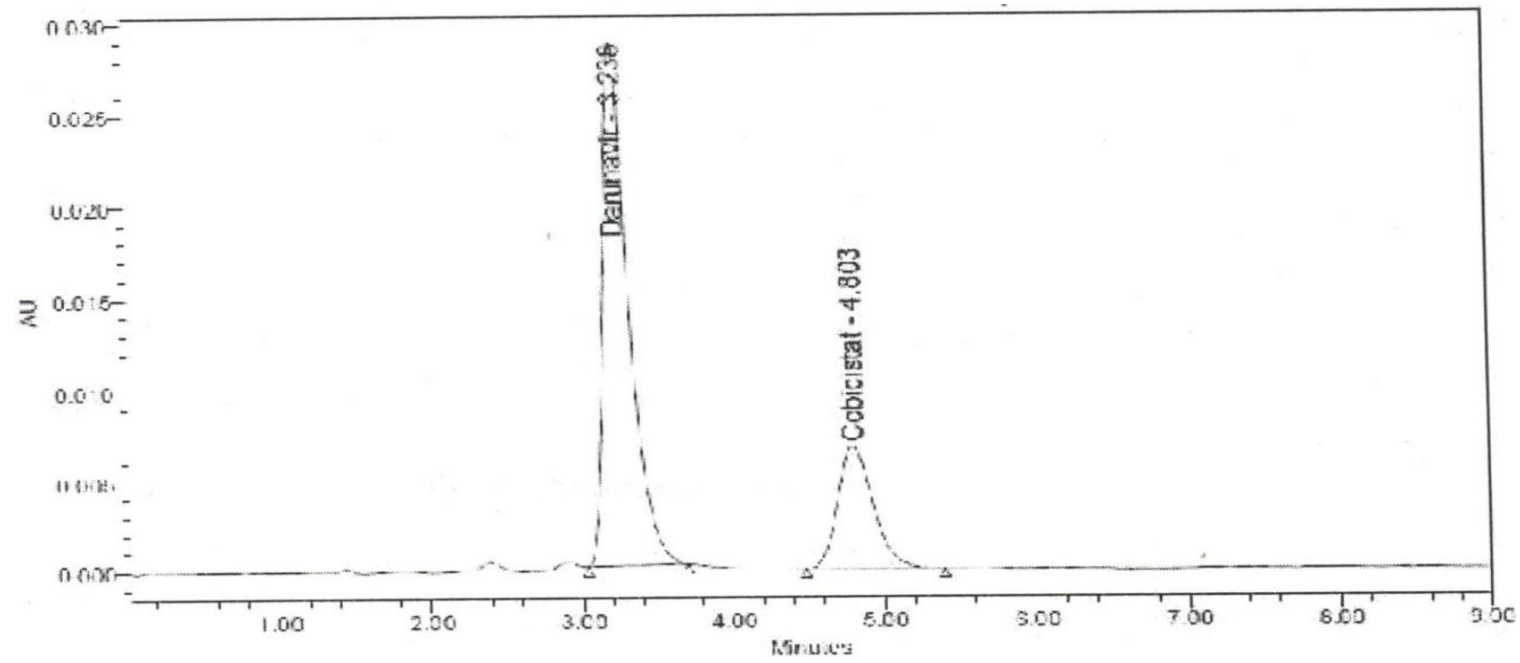

Fig. 22: Chromatogram-2 for intermediate precision of Darunavir and Cobicistat

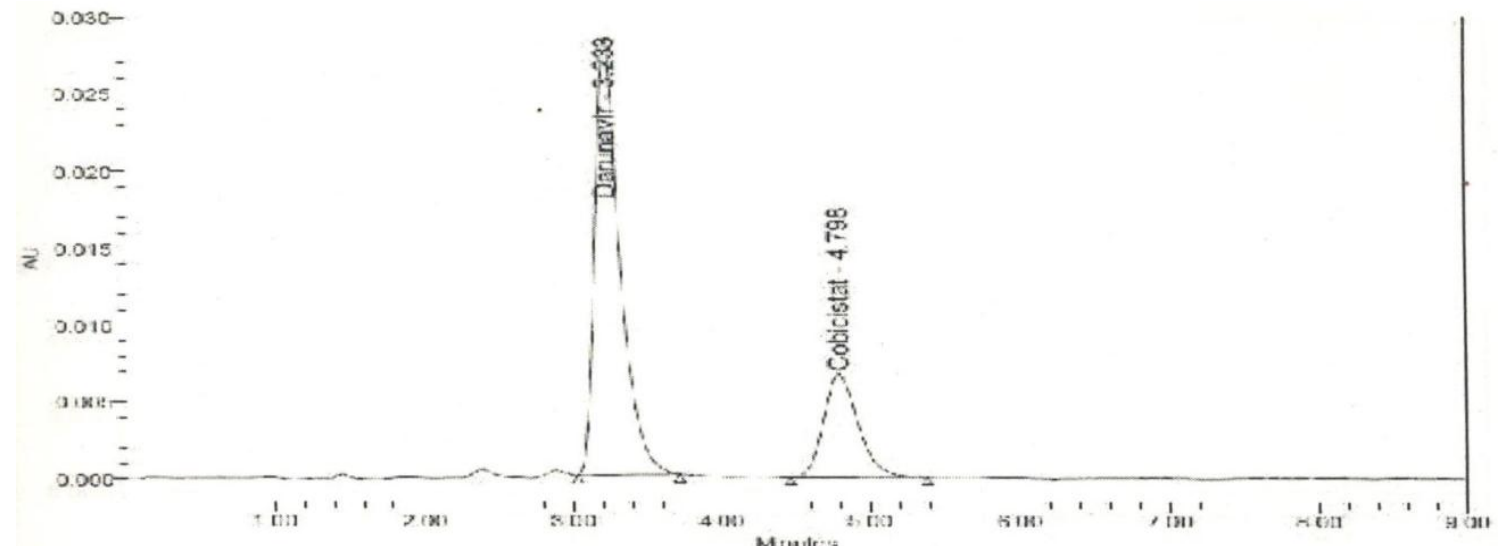

Fig. 23: Chromatogram-3 for intermediate precision of Darunavir and Cobicistat

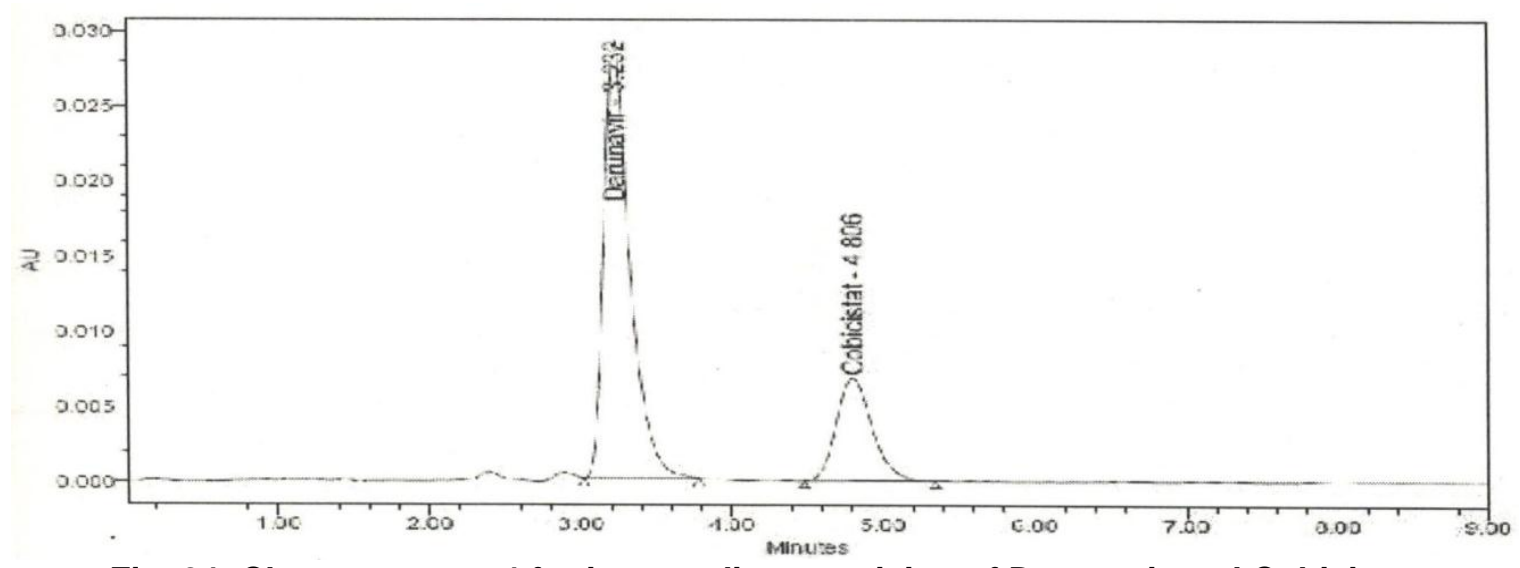

Fig. 24: Chromatogram-4 for intermediate precision of Darunavir and Cobicistat 


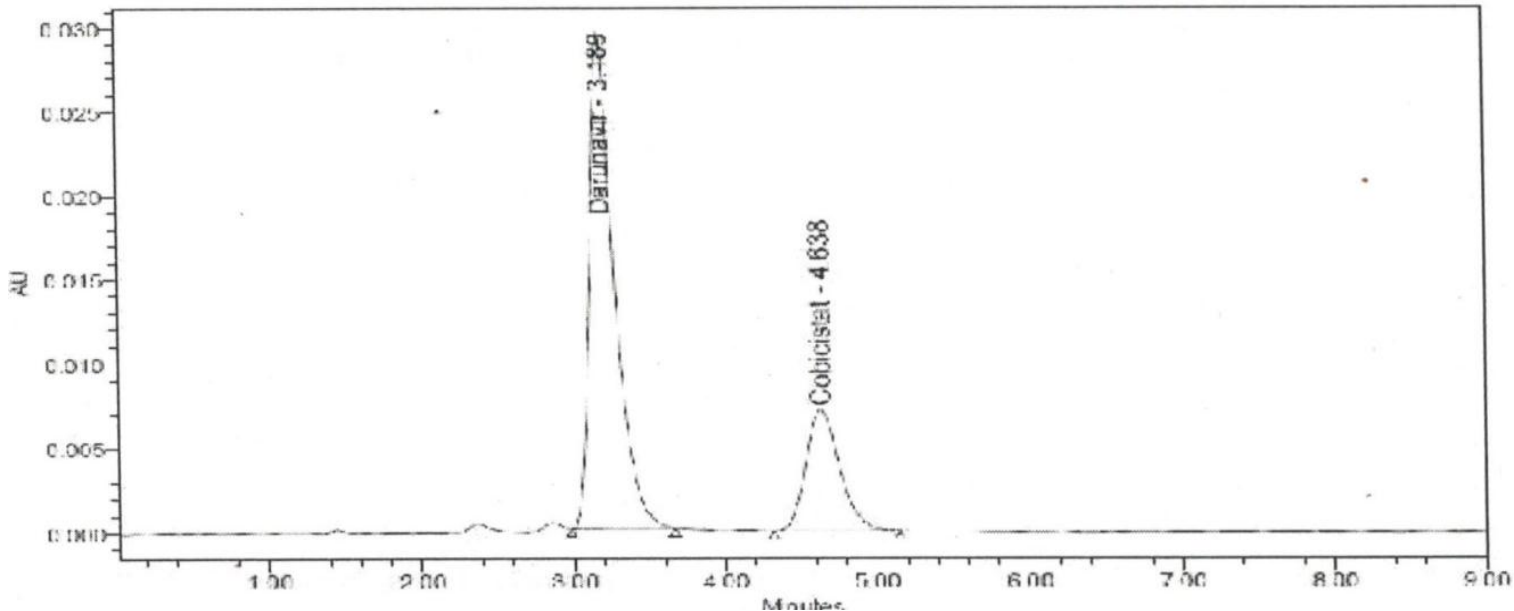

Fig. 25: Chromatogram-5 for intermediate precision of Darunavir and Cobicistat

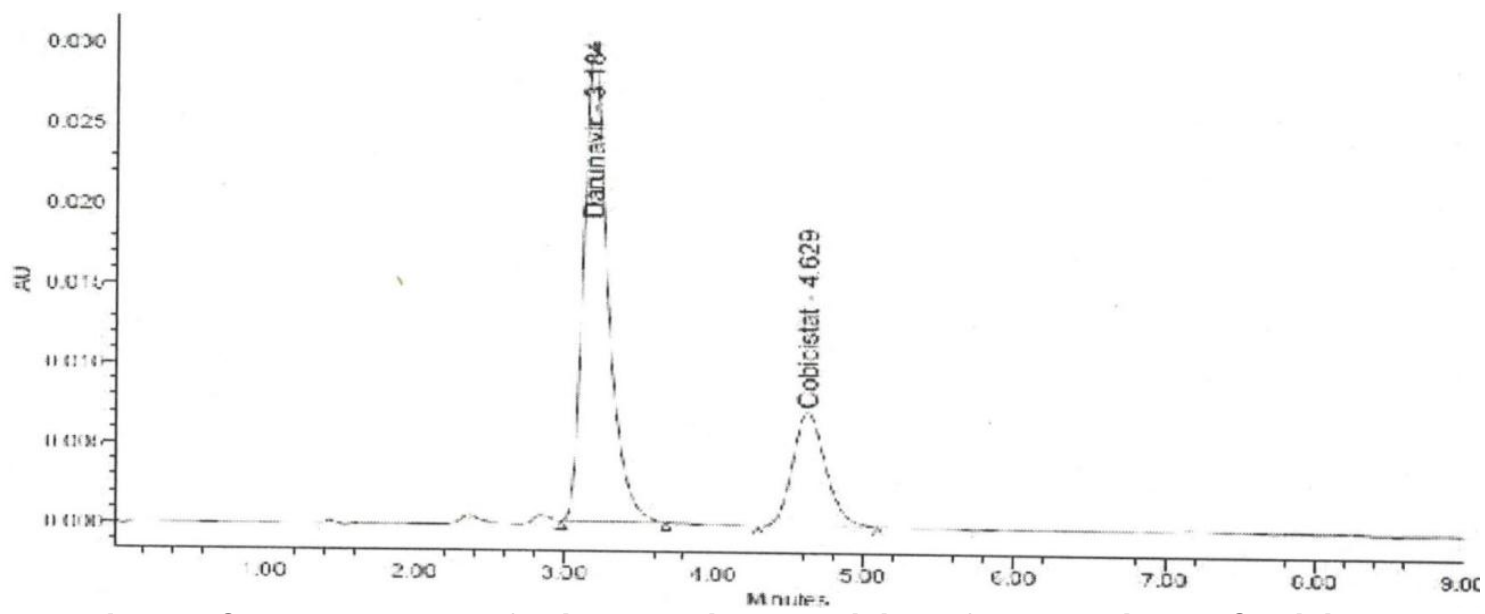

Fig. 26: Chromatogram-6 for intermediate precision of Darunavir and Cobicistat

Table 1: System suitability studies

of Darunavir and Cobicistat

\begin{tabular}{|c|c|c|c|}
\hline Parameter & Darunavir & Cobicistat & Acceptance criteria \\
\hline Retention time & 3.233 & 4.805 & --- \\
\hline No. of theoretical plates & 2644.98 & 3766.98 & NLT 2000 \\
\hline Tailing factor & 1.33 & 1.20 & NMT 2.0 \\
\hline Resolution & 4.12 & NLT 2.0 \\
\hline
\end{tabular}

Table 2: Results of recovery experiments of darunavir and cobicistat

\begin{tabular}{|c|c|c|c|c|c|}
\hline \multicolumn{2}{|c|}{$\begin{array}{c}\text { Preanalysed } \\
\text { amount }(\mu \mathrm{g} / \mathrm{mL})\end{array}$} & \multicolumn{2}{|c|}{$\begin{array}{c}\text { Spiked } \\
\text { amount }(\mu \mathrm{g} / \mathrm{mL})\end{array}$} & \multicolumn{2}{|c|}{$\%$ recovered } \\
\hline Darunavir & Cobicistat & Darunavir & Cobicistat & Darunavir & Cobicistat \\
\hline 120 & 45 & 60 & 22.5 & \multirow{3}{*}{99.59} & \multirow{3}{*}{99.87} \\
\hline 120 & 45 & 60 & 22.5 & & \\
\hline 120 & 45 & 60 & 22.5 & & \\
\hline 120 & 45 & 120 & 45 & \multirow{3}{*}{99.68} & \multirow{3}{*}{101.67} \\
\hline 120 & 45 & 120 & 45 & & \\
\hline 120 & 45 & 120 & 45 & & \\
\hline 120 & 45 & 180 & 67.5 & \multirow{3}{*}{98.59} & \multirow{3}{*}{101.67} \\
\hline 120 & 45 & 180 & 67.5 & & \\
\hline \multirow[t]{4}{*}{120} & 45 & 180 & 67.5 & & \\
\hline & & & MEAN & 99.28 & 101.07 \\
\hline & & & SD & 0.605 & 1.039 \\
\hline & & & \%RSD & 0.61 & 1.03 \\
\hline
\end{tabular}


Table 3: Results of method precision of darunavir and cobicistat

\begin{tabular}{|c|c|c|}
\hline \multirow{2}{*}{$\begin{array}{c}\text { Sample } \\
\text { number }\end{array}$} & \multicolumn{2}{|c|}{ Method precision } \\
\cline { 2 - 3 } & Darunavir & Cobicistat \\
\hline 1 & 352960 & 112771 \\
\hline 2 & 350827 & 111383 \\
\hline 3 & 352176 & 112738 \\
\hline 4 & 350147 & 112476 \\
\hline 5 & 344319 & 112658 \\
\hline MEAN & 350085.8 & 112405.2 \\
\hline SD & 3407.311 & 582.74 \\
\hline \% RSD & $\mathbf{0 . 9 7}$ & $\mathbf{0 . 5 2}$ \\
\hline
\end{tabular}

Table 4: Results of intermediate precision of darunavir and cobicistat

\begin{tabular}{|c|c|c|}
\hline \multirow{2}{*}{ S.No. } & \multicolumn{2}{|c|}{ Area } \\
\cline { 2 - 3 } & darunavir & Cobicistat \\
\hline 1 & 332365 & 108816 \\
\hline 2 & 340012 & 110789 \\
\hline 3 & 335294 & 109615 \\
\hline 4 & 342701 & 110643 \\
\hline 5 & 337945 & 109819 \\
\hline 6 & 342525 & 111360 \\
\hline MEAN & 1442223 & 815370.3 \\
\hline SD & 18375.8 & 2844.8 \\
\hline \% RSD & $\mathbf{1 . 2 7}$ & $\mathbf{0 . 3 5}$ \\
\hline
\end{tabular}

Table 5: Robustness study for darunavir and cobicistat

\begin{tabular}{|c|c|c|c|c|}
\hline \multirow{2}{*}{ Condition } & \multicolumn{2}{|c|}{ darunavir } & \multicolumn{2}{c|}{ cobicistat } \\
\cline { 2 - 5 } & $\begin{array}{c}\text { Tailing } \\
\text { factor }\end{array}$ & $\begin{array}{c}\text { Theoretical } \\
\text { plates }\end{array}$ & Tailing factor & $\begin{array}{c}\text { Theoretical } \\
\text { plates }\end{array}$ \\
\hline Flow rate at $1.0 \mathrm{~mL} / \mathrm{min}$ & 1.48 & 2860.09 & 1.18 & 3131.66 \\
Flow rate at $1.2 \mathrm{~mL} / \mathrm{min}$ & 1.33 & 2644.98 & 1.20 & 3766.53 \\
Flow rate at $1.4 \mathrm{~mL} / \mathrm{min}$ & 1.44 & 2847.37 & 1.20 & 3055.53 \\
\hline Mobile phase: & 1.5 & 2071 & 1.2 & 3266 \\
$0.1 \%$ TEA:Methanol (40:60) & 1.3 & 2644 & 1.2 & 3766 \\
$0.1 \%$ TEA:Methanol (30:70) & 1.4 & 2732 & 1.2 & 2894 \\
$0.1 \%$ TEA:Methanol(20:80) & & \multicolumn{4}{|}{} \\
\hline
\end{tabular}

\section{REFERENCES}

1. Raveendra Babu G, Lakshmana Rao $\mathrm{A}$ and Venkateswara Rao J. Development And Validation of Novel HPLC Method for Estimation of Darunavir In Pharmaceutical Formulations, International Journal of Research in Pharmacy and Chemistry. 2013;3(2):438-443.

2. Reddy BV, Jyothi G, Reddy BS, Raman NV, Reddy KS and Rambabu C. Stability-indicating HPLC method for the determination of darunavirethanolate. J Chromatogr Sci. 2013;51(5):471-6.

3. Raveendra B Ganduri, Ramprasad A Lanka, Srinivasu Pamidi, Jayachandra $\mathrm{R}$, Peddareddigari and JVLNS Rao. New RP-HPLC Method For The Determination of Darunavir
Ethanolate Both In Bulk and Marketed Dosage Formulations. World Journal of Pharmaceutical Research. 2015;4(3):1276-1283.

4. Raghu Ram Jampala, Kiran Kumar $V$ and Appala Raju Nemala. Development and Application of Liquid Chromatographic Method for Simultaneous Determination of Elvitegravir, Tenofovir Disoproxil Fumarate, Emtricitabine, and Cobicistat in Fixed Dosage Form, Pharmaceutical Methods. 2014;5(1):7-13.

5. Kalyani $\mathrm{K}$ and Anuradha V. A Stability-Indicating High Performance Liquid chromatographic method for the determination of cobicistat. Int $\mathrm{J}$ Pharm Drug Anal. 2015;4(3):117125. 
6. Urooj Fatima T, Mamatha I and Rajesh Goud Gajula A. novel RPHPLC method development and validation of Cobicistat in bulk drug and tablet dosage form. Der Pharmacia Sinica. 2014;5(5):99-105.

7. Putchakayala Purnachandra Rao, Dondeti Mogili Reddy and
Ramachandran D. Stability indicating HPLC method for simultaneous estimation of emtricitabine, tenofovirdisoproxyl fumarate, cobicistat and elvitegravir in pharmaceutical dosage form. World Journal of pharmaceutical Sciences. 2014;2(12):1822-1829. 